\title{
Alcohol Use and Cancer in the European Union
}

\author{
Jürgen Rehm ${ }^{a-g} \quad$ Kevin D. Shield ${ }^{b}, d, f$ \\ anstitute of Clinical Psychology and Psychotherapy \& Center for Clinical Epidemiology and Longitudinal Studies, \\ Technische Universität Dresden, Dresden, Germany; ${ }^{b}$ Institute for Mental Health Policy Research, Centre for \\ Addiction and Mental Health, Toronto, ON, Canada; 'Department of Psychiatry, University of Toronto, Toronto,

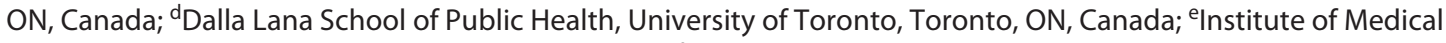 \\ Science, University of Toronto, Toronto, ON, Canada; ${ }^{\mathrm{C} C a m p b e l l ~ F a m i l y ~ M e n t a l ~ H e a l t h ~ R e s e a r c h ~ I n s t i t u t e, ~ C e n t r e ~}$ \\ for Addiction and Mental Health, Toronto, ON, Canada; 9Department of International Health Projects, Institute \\ for Leadership and Health Management, I.M. Sechenov First Moscow State Medical University, Moscow, Russian \\ Federation
}

\section{Keywords}

Alcohol use - Causes of death - Cancer - European Union . Population health . Prevention paradox

\section{Abstract}

Background: Cancers constitute a major non-communicable disease category globally and in the European Union (EU). Summary: Alcohol use has been established as a major cause of cancer in humans. Principal cancer agencies agree that the following cancer sites are causally impacted by alcohol: lip and oral cavity, pharynx (excluding nasopharynx), oesophagus, colon and rectum, liver, (female) breast, and larynx. For all of these cancer sites, there is a dose-response relationship with no apparent threshold: the higher the average level of consumption, the higher the risk of cancer incidence. In the EU in 2016 , about 80,000 people died of alcohol-attributable cancer, and about 1.9 million years of life were lost due to premature mortality or due to disability. Key messages: Given the above-described impact of alcohol on cancer, public awareness about the alcohol-cancer link needs to be increased. In addition, effective alcohol policy measures should be implemented. As a large part of alcohol-

karger@karger.com www.karger.com/ear

Karger $\stackrel{\text { ' }}{5}$

GOPEN ACCESS
(C) 2020 The Author(s)

Published by S. Karger AG, Basel

This article is licensed under the Creative Commons AttributionNonCommercial-NoDerivatives 4.0 International License (CC BY NC-ND) (http://www.karger.com/Services/OpenAccessLicense). Usage and distribution for commercial purposes as well as any distribution of modified material requires written permission. attributable cancers are in low and moderate alcohol users, in particular for females, general population measures such as increases in taxation, restrictions on availability, and bans on marketing and advertisement are best suited to reduce the alcohol-attributable cancer burden.

(C) 2020 The Author(s)

Published by S. Karger AG, Basel

\section{Introduction}

Cancers constitute a major non-communicable disease category [1]. It has been estimated that the global cancer burden rose to 18.1 million new cases and 9.6 million deaths in 2018 [2]. One in 5 men and 1 in 6 women worldwide develop cancer during their lifetime, and 1 in 8 men and 1 in 11 women die from the disease. As cancers affect people relatively late in their life-course, their impact is most pronounced in regions with high life expectancy, such as the European Union (EU) [3].

Cancer is affected by the same risk factors as other non-communicable diseases: tobacco smoking, alcohol use, physical activity, and nutrition [4], and these risk fac- 
Table 1. Summary of the evidence for a causal relationship between alcohol consumption and the risk of various cancer subtypes [7, 12 , $15,59-67]$

\begin{tabular}{|c|c|c|c|}
\hline \multirow{2}{*}{$\begin{array}{l}\text { Cancer site (ICD-10 code) } \\
\text { and level of causality }\end{array}$} & \multicolumn{3}{|l|}{ Evidence } \\
\hline & $\begin{array}{l}\text { International Agency for } \\
\text { Research on Cancer }[7,12]\end{array}$ & $\begin{array}{l}\text { World Cancer Research Fund International } \\
\text { (Continuous Update Project) }\end{array}$ & $\begin{array}{l}\text { L'Institut National Du } \\
\text { Cancer France [15] }\end{array}$ \\
\hline \multicolumn{4}{|l|}{ Causally related to alcohol consumption } \\
\hline Oral cavity $(\mathrm{C} 02-06)$ & Sufficient evidence & Convincing [59] & Convincing \\
\hline Oropharynx (C01, C09-10) & Sufficient evidence & Convincing [59] & Convincing \\
\hline Hypopharynx (C12-13) & Sufficient evidence & Convincing [59] & Convincing \\
\hline Oesophagus (C16) & Sufficient evidence & - & \\
\hline Oesophagus - adenocarcinoma & - & Limited - no conclusion $[60]$ & Insufficient evidence \\
\hline Oesophagus - squamous cell carcinoma & - & Convincing $[60]$ & Convincing \\
\hline Colon (C18) & Sufficient evidence & Convincing (men)/probable (women) [61] & Convincing \\
\hline Rectum (C19-20) & Sufficient evidence & Convincing (men)/probable (women) [61] & Convincing \\
\hline Liver (C22) & Sufficient evidence & Convincing [26] & Convincing \\
\hline Larynx (C32) & Sufficient evidence & Convincing [59] & Convincing \\
\hline Breast (female) (C50) & Sufficient evidence & Convincing [62] & Convincing \\
\hline \multicolumn{4}{|l|}{ Causality not established } \\
\hline Stomach (C16) & - & Probable [63] & Controversial results \\
\hline Gallbladder (C23) & - & Limited - no conclusion [64] & Not established \\
\hline Pancreas (C25) & Observed association & Limited - suggestive (heavy consumption) [65] & Controversial results \\
\hline Prostate (C61) & - & Limited - no conclusion $[66]$ & $\begin{array}{l}\text { Not established - may be } \\
\text { associated at higher alcohol } \\
\text { consumption levels }\end{array}$ \\
\hline Kidney (C64-65) & $\begin{array}{l}\text { Evidence suggesting lack of } \\
\text { carcinogenicity }\end{array}$ & Probable (for alcohol intake up to $30 \mathrm{~g} /$ day) [67] & Insufficient data \\
\hline
\end{tabular}

ICD, International Classification of Diseases.

tors have also been included in the World Health Organization's (WHO's) monitoring framework for these diseases with concrete targets to be reached by 2025 [5].

This article will focus on alcohol use as a risk factor for cancer and will discuss 5 specific points:

- Which cancer subtypes are causally affected by alcohol?

- What are the risk relations between alcohol and cancer subtypes?

- What is the burden of alcohol-attributable cancer in the EU?

- What are the trends in alcohol-attributable cancers?

- What policy measures can be taken?

\section{Main Text}

\section{Which Cancer Subtypes Are Causally Affected by Alcohol?}

Alcoholic beverages have long been established as being causally related to the risk of cancer in humans [6-8]; ethanol (pure alcohol) is a procarcinogen found within all alcoholic beverages [9]. As per the definition of the International Agency for Research on Cancer (IARC) [10], the procarcinogen label is applied to substances that transform into carcinogens by their metabolism.

As with most other procarcinogens, alcohol affects different subtypes of cancer. Internationally, different organizations regularly conduct comprehensive reviews on the risk factors for cancer, and thus on the subtypes of cancer affected by alcohol use as follows:

- The IARC [10], part of the WHO, and thus under the governance of the United Nations (UN), has established a monograph program, where knowledge is regularly updated about the carcinogenicity of different risk factors using standardized protocols and by inviting international experts' opinions [11]. Alcohol use has been central to 2 separate monographs $[6,7]$ and part of a large review covering all lifestyle factors [12].

- Various publications of the Continuous Update Project of the World Cancer Research Fund International [13], an ongoing programme which analyses global research on how diet, nutrition, and physical activity af- 


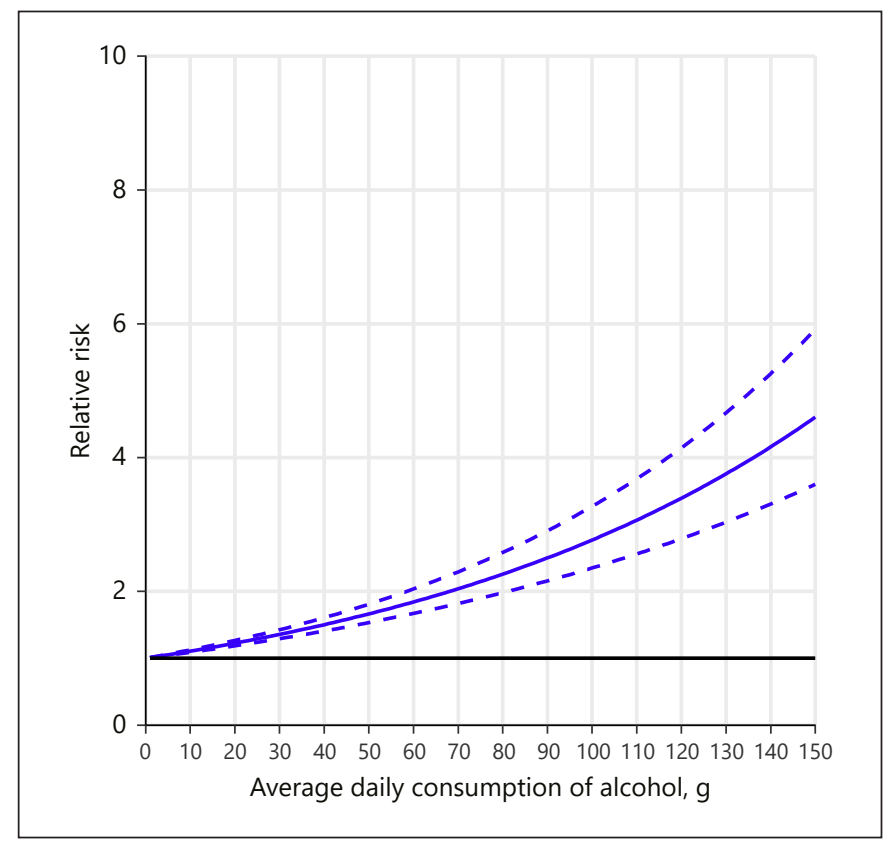

Fig. 1. Relative risks and 95\% confidence intervals for breast cancer among female alcohol users by average volume of drinking (as compared to lifetime abstainers). (Source: own calculation based on [16]).

fect cancer risk and survival, have examined alcohol use as a risk factor for cancer.

- In the EU, the French National Cancer Institute [14] conducted a comprehensive review on the risk relationship between alcohol and cancer in 2007 [15].

All 3 of the above review systems converged to a large degree on the subtypes of cancer affected by alcohol use, and the results can be found in Table 1. Thus, the following cancer types will be included in this article as being causally related to alcohol: lip and oral cavity, pharynx (excluding nasopharynx), oesophagus, colon and rectum, liver, (female) breast, and larynx.

\section{What Are the Risk Relations between Alcohol and Cancer Subtypes?}

Two systematic reviews and meta-analyses provide the most comprehensive and comparable overviews on risk relations $[16,17]$, and serve as the basis for the latest comparative risk analyses for alcohol (for an overview of comparative risk assessments, see [18]). Consistent with the use of WHO data for outcomes, we decided to use the Bagnardi et al. [16] analyses (except for the risk of liver cancer, which was based on [19]). The above-specified risk relations were also used in the Global Status Report

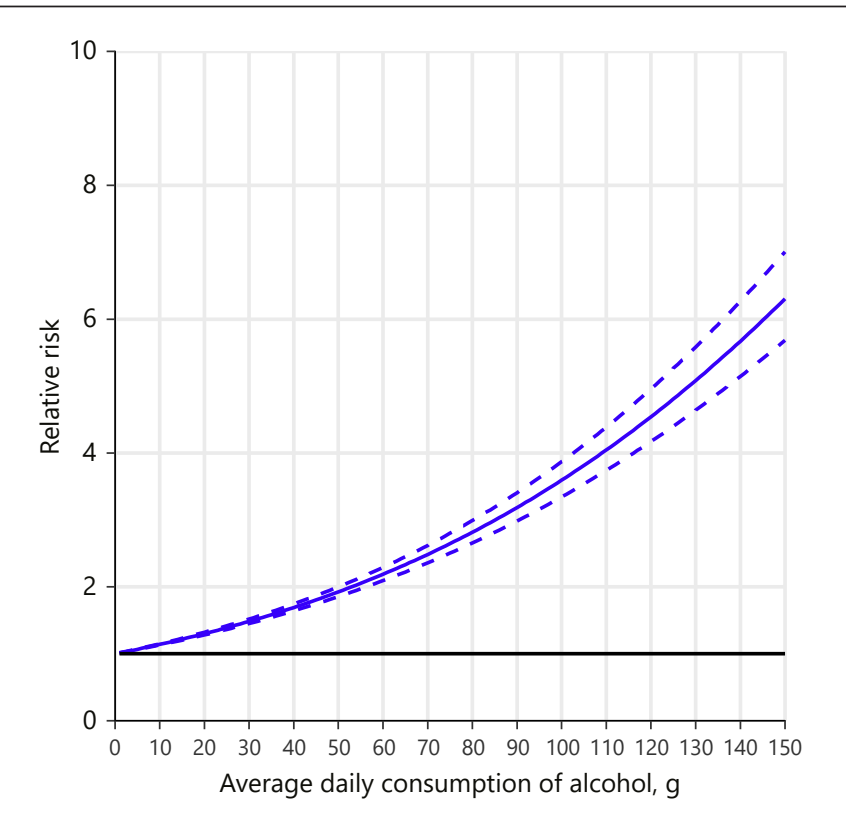

Fig. 2. Relative risks and 95\% confidence intervals for oesophageal cancer among alcohol users by average volume of drinking (as compared to lifetime abstainers). (Source: own calculation based on [16]).

on Alcohol and Health [20] and the World Cancer Report [21].

Risk relations can be characterized as follows (while figures for all alcohol-attributable cancer types cannot be provided, see the exemplary illustrations in Fig. 1, 2; all dose-response relationships between levels of alcohol use and cancer endpoints can be found in $[22,23])$ :

- All dose-response curves for the cancer types identified as causal (see above) show no protective effects at any level of alcohol use, and there is increasing risk with higher levels of consumption. The protective effect for these cancer types reported in some publications is likely due to comparisons made to current abstainers, a group which includes former drinkers with elevated risk (for cancer, see [19, 24-26]), and lifetime abstainers [8]. It should be noted that the effects of alcohol use on cancer involve a lag time, usually modelled at 10 years [20,27].

- While there is a clear dose-response relationship, with risks reported as lower at lower levels of consumption, there is no safe lower limit for alcohol use $[7,8]$. For breast cancer, biological studies [28], individual and aggregate-level meta-analyses based on either cohort or case-control studies (individual-level pooled analy- 
Table 2. Level of drinking and attributable cancers in Germany, 2018 (based on alcohol exposure data for 2008) [16, 35, 68]

\begin{tabular}{|c|c|c|c|c|c|c|}
\hline Disease condition & $\begin{array}{l}\text { Drinking category } \\
\text { [35] }\end{array}$ & $\begin{array}{l}\% \text { of } \\
\text { population }\end{array}$ & $\begin{array}{l}\mathrm{RR} \\
{[16]}\end{array}$ & $\begin{array}{l}\text { Decomposition of } \\
\text { contributions (for } \\
\text { formulas, see [68]) }\end{array}$ & Excess risk & $\begin{array}{l}\text { Contribution to } \\
\text { excess risk, \% }\end{array}$ \\
\hline \multirow{4}{*}{ Breast cancer (women) } & $0-20 \mathrm{~g}$ & 51.3 & 1.11 & 0.5691 & 0.056 & 20.0 \\
\hline & $20-40 \mathrm{~g}$ & 13.3 & 1.36 & 0.1811 & 0.048 & 17.2 \\
\hline & $>40 \mathrm{~g}^{\circ}$ & 9.9 & 2.77 & 0.2736 & 0.175 & 62.7 \\
\hline & \multicolumn{3}{|c|}{ PAF (whole population) } & \multicolumn{3}{|l|}{$12.8 \%$} \\
\hline \multirow[t]{4}{*}{ Colon cancer (women) } & Abstainer & 25.5 & 1.00 & 0.2549 & 0 & 0.0 \\
\hline & $0-20 \mathrm{~g}$ & 51.3 & 1.07 & 0.5467 & 0.034 & 23.1 \\
\hline & $20-40 \mathrm{~g}$ & 13.3 & 1.21 & 0.1609 & 0.028 & 19.1 \\
\hline & $>40 \mathrm{~g}$ & 9.9 & 1.85 & 0.084 & 0.084 & 57.8 \\
\hline \multirow{5}{*}{ Colon cancer (men) } & $0-20 \mathrm{~g}$ & 35.0 & 1.07 & 0.3728 & 0.023 & 6.5 \\
\hline & $20-40 \mathrm{~g}$ & 18.7 & 1.21 & 0.2255 & 0.039 & 11.0 \\
\hline & $>40 \mathrm{~g}$ & 34.3 & 1.85 & 0.6345 & 0.292 & 82.5 \\
\hline & & & & 1.3537 & 0.354 & 100.0 \\
\hline & PAF & & & $26.1 \%$ & & \\
\hline
\end{tabular}

$\mathrm{RR}$, relative risk (relative to abstainers); PAF, populationattributable fraction. The rows highlighted in bold refer to the proportion of all cancers of that type which were caused by alcohol use.

sis: [29]); aggregate level meta-analyses [30, 31]; and large-scale individual studies [32] converge: even average alcohol intake as low as $10 \mathrm{~g}$ of ethanol per day or lower - the most common size of a standard drink globally is $10-12 \mathrm{~g}$ of ethanol - is associated with a significantly increased risk of breast cancer.

- The dose-response curves between levels of alcohol use and cancer are relatively flat and almost linear (for a further discussion of dose-response curves and the different dimensions of alcohol use relevant for disease, see [33]), so a large part of the burden occurs in light to moderate drinkers [34], especially among women. The 2 most frequent cancers in Germany are breast cancer and colorectal cancer (see Table 2; calculations for 2018, based on alcohol exposure for 2008 from [35] and risk relations from [16]). More than $20 \%$ of the alcohol-attributable cancer cases in these categories are seen in women who consume less than 2 drinks a day. For men, $8 \%$ of all alcohol-attributable colorectal cancer cases fall into these categories. This is another example of the so-called preventive paradox [36], which can be characterized by in- creasing dose-response relationships (the higher the alcohol use, the higher the risk of cancer), but still a large part of cancer cases are in relatively low drinking categories because there are so many more people drinking this way (as illustrated for Germany, this mainly concerns women; most of women with alcoholattributable breast and colorectal cancers drink less than $45 \mathrm{~g}$ pure alcohol - or four standard drinks per day). For most other European countries, light drinking causes higher proportions of alcohol-attributable cancers (as Germany has one of the highest prevalence of heavy alcohol use in the EU and the world). Notably, Table 2 was based on all alcohol being sold also being consumed. If we base Table 2 on alcohol consumption surveys only, the majority of alcohol-attributable deaths in female breast or colorectal cancers would be below $20 \mathrm{~g}$ of average drinking. As a consequence of the distribution of alcohol-attributable cancer, a population preventive strategy is best aimed at reducing the alcohol-attributable cancer burden [37, 38]. 


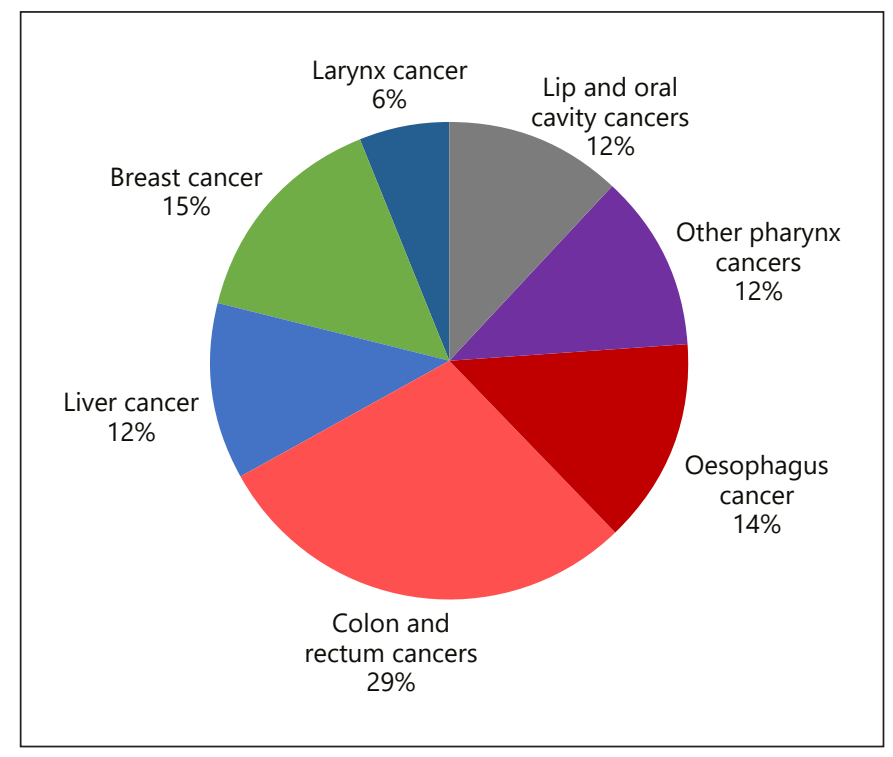

Fig. 3. Proportions of different categories of the alcohol-attributable cancer burden, 2016 (total alcohol-attributable disability-adjusted life years lost: 1,880,490). (Source: Own calculations based on [23]).

What Are the Levels of Alcohol-Attributable Cancer in the EU?

Based on the analyses of Shield and colleagues [23], there were almost 80,000 alcohol-attributable cancer deaths in Europe in 2016 (78,985, 95\% confidence interval [CI]: 75,498-91,102; women: $22,778,95 \%$ CI: $18,985-$ 26,622; men: 56,207, 95\% CI: 54,142-66,709). In terms of the burden of disease in the same year, the estimate was almost 1.9 million cancer disability-adjusted life years lost $(1,880,490,95 \%$ CI: $1,809,078-2,154,084$; women: 531,377, 95\% CI: 450,307-614,370; men: 1,349,113, 95\% CI: 1,306,596-1,591,898). Indeed, alcohol use is one of the main known risk factors for cancer in the EU; in a recent comprehensive study on risk factors for cancer in France, only tobacco smoking was reported to cause higher cancer incidence [39].

Figure 3 provides an overview of the burden of disease for different categories of alcohol-attributable cancers. Colon and rectum, and female breast cancers were the highest contributors to this burden.

\section{What Are the Trends in Alcohol-Attributable}

Cancers?

Figures 4 and 5 display the alcohol-attributable ageadjusted cancer rates since 2000. Rates for both deaths and disability-adjusted life years lost have been decreas-

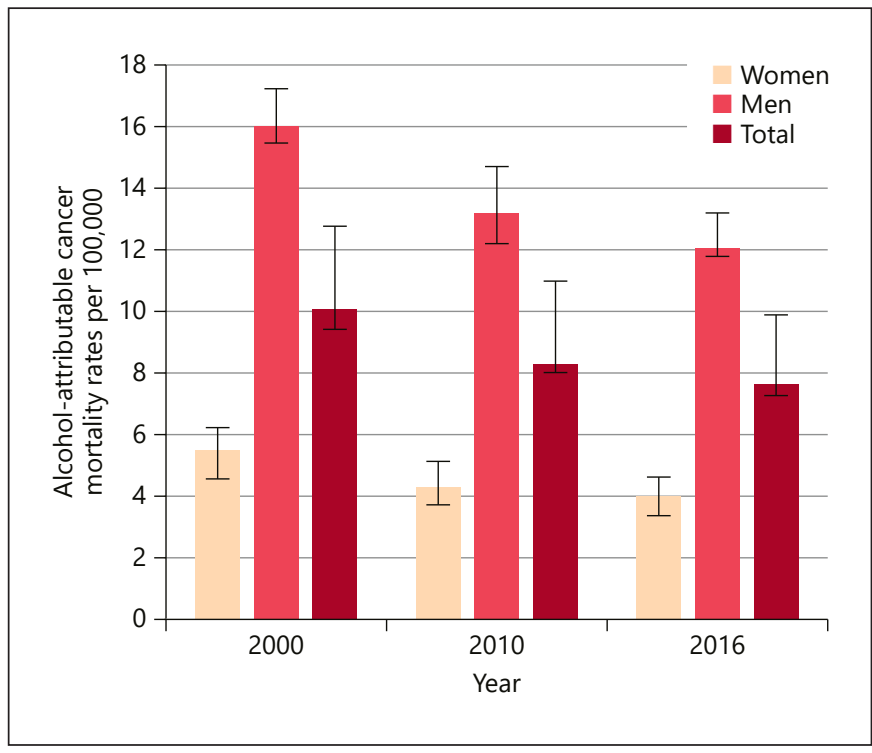

Fig. 4. Alcohol-attributable cancer mortality rates per 100,000 since 2000 and 95\% confidence intervals. (Source: Own calculations based on Shield et al. [23]).

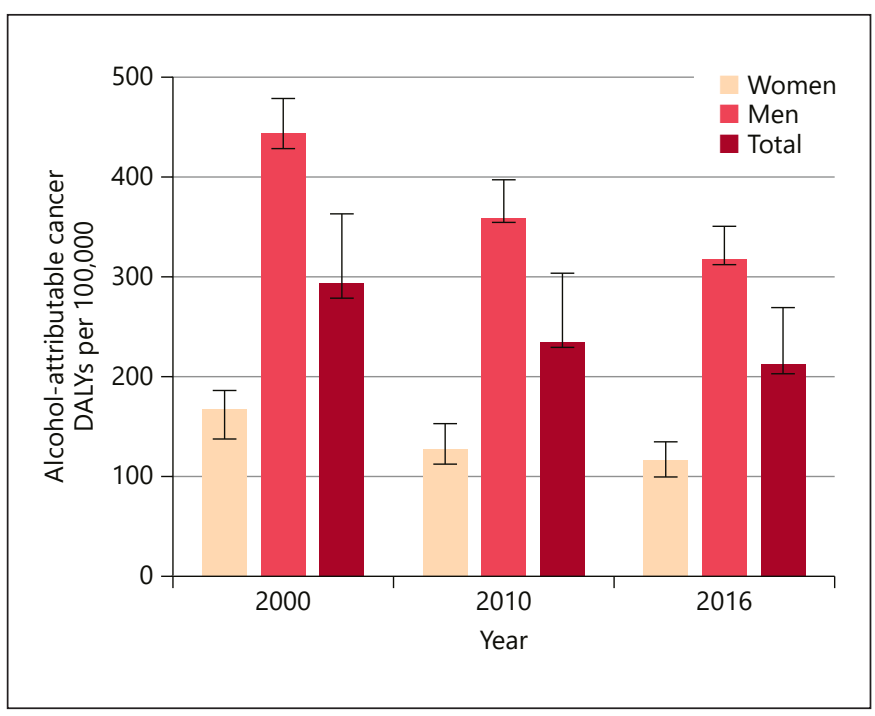

Fig. 5. Alcohol-attributable cancer disability-adjusted life years lost per 100,000 since 2000 and 95\% confidence intervals. (Source: Own calculations based on Shield et al. [23])

ing, following overall trends in average levels of alcohol use in the EU $[28,35]$. Note that these trends mirror the alcohol use trends between 1990 and 2006, due to the latency period of 10 years. 
These trends also reflect secular trends (for trends in the overall alcohol-attributable burden of disease, see online suppl. Figures A1 and A2; for all online suppl. material, see www.karger.com/doi/10.1159/000507017). While alcohol-attributable cancer indicators decreased, alcohol-attributable cancer harm is still high in the EU (see above). However, the downward trend is expected to slow down or possibly reverse in the future based on more recent trends in both alcohol use $[35,40,41]$ and cancer mortality [42].

\section{What Policy Measures Can Be Taken?}

Although it is well established scientifically that alcohol is a procarcinogen and alcohol use can cause cancer (see above), this knowledge has still not entered into broad public awareness in most countries [43]. Even for people who indicated an awareness of such an impact, their knowledge was not necessarily specific to alcohol, but rather part of a general belief that "everything causes cancer" [44]. This indicates an urgent need to inform the general population about the alcohol-cancer link.

We can only speculate about the lack of public awareness about the alcohol-cancer link. The fact that media coverage of alcohol use has concentrated on the discussion of a cardioprotective effect (for an overview, see [45]) seems to have played a role. This coverage has been fuelled in part by marketing campaigns by the alcohol industry, which concentrated on the beneficial potential of alcohol use, and tried to put into question some of the evidence of an alcohol-cancer link [46]. Finally, while alcohol has been identified as the second largest risk factor for cancer in a country like France [39], the attributable fractions are relatively small and there is no type of cancer where alcohol causes the majority of incident cases (e.g., [23]), thus making it harder to create a link in the minds of the public unlike the recognition of the link between alcohol and liver cirrhosis [47] and tobacco and lung cancer (see [48] for an overview).

Given the marked risk of usual alcohol intake in most societies (see [35] for descriptions of usual intake), one way of disseminating this information to communities at large would be to use specific cancer-warning labels [49]. While there is limited evidence that such labels lead to changes in alcohol drinking behaviours (e.g., [50]), the fact that alcohol is a procarcinogen needs to be communicated even if such information does not necessarily lead to modified behaviour. Also, current evidence of minimal behavioural change in alcohol use resulting from cancerwarning labels may be due in part to the more general and non-specific messaging on the labels used to date on al- coholic beverages, and to the small size of the labels used (for experiences regarding the use of labels in tobacco packaging, see [51, 52]). A label containing a message such as "alcohol use can cause cancer" may be more effective, especially if presented along with a picture of an oesophageal or other cancer site; however, the only field trial of the effectiveness of a specific cancer label had to be stopped due to interference from the alcohol industry [53]. Effective dissemination of information regarding the carcinogenicity of alcohol requires educational materials to be provided to the public: if alcohol were introduced as a food item today in its usual forms, it would likely fail to pass current safety regulations $[54,55]$. In providing these educational materials, the effects of competing interests, such as pervasive product marketing or misinformation by the alcohol industry, should be taken into account $[46,56]$.

In addition, as indicated above, the dose-response relationship between the level of alcohol use and cancer suggests that the most important policies would be population-level measures, such as higher taxation of alcoholic beverages to increase prices and reduce affordability, restrictions on availability such as reduced hours of sale, and a ban on marketing and advertisement [57]. Only increased taxation of alcoholic beverages is mentioned in the most recent fact sheet of the EU's Beating Cancer Plan [58].

\section{Conclusion}

Alcohol is an established procarcinogen, and alcohol use has been established as a major cause of cancer. No apparent threshold exists. Given this situation, population awareness of the impact of alcohol use on the risk of cancer needs to be established. Furthermore, overall consumption of alcohol should be reduced in the EU, which is one of the global regions with high per capita consumption.

\section{Acknowledgements}

The authors acknowledge that Dr. Bagnardi supplied the formulas to describe the risk relations between average volume of alcohol consumption and different types of cancer. We also thank A. Otto for copy-editing and referencing the article.

\section{Disclosure Statement}

The authors have no conflicts of interest to declare. 


\section{Funding Sources}

The first author also acknowledges funding from the Canadian Institutes of Health Research's Institute of Neurosciences, Mental Health and Addiction (Canadian Research Initiative in Substance Misuse Ontario Node Grant SMN-13950). This article was also supported in part by the EU Health Programme 2014-2020 under a service contract with the Consumers, Health, Agriculture and Food Executive Agency (CHAFEA) acting under a mandate from the European Commission (FAR SEAS - 20187106). The information and views set out in this article are those of the authors and do not necessarily reflect the official opinion of the Commission/Executive Agency. The Commission/Executive Agency do not guarantee the accuracy of the data included in this study. Neither the
Commission/Executive Agency nor any person acting on the Commission's/Executive Agency's behalf may be held responsible for the use that may be made of the information contained therein.

Finally, this contribution was enabled by the WHO Collaborating Centre at the Centre for Addiction and Mental Health in Toronto, the Public Health Agency of Catalonia, and the WHO Collaborating Centre at the Catalan Institute of Oncology. We thank Pol Rovira for assisting with Table 2.

\section{Author Contributions}

Both authors were involved in all steps of the review, analyses, and writing.

\section{References}

1 World Health Organization. Global health estimates (GHE) Geneva, Switzerland; 2019 [cited 2019 Oct 21]. Available from: https:// www.who.int/healthinfo/global_burden_disease/en/.

2 International Agency for Research on Cancer (IARC). Global cancer observatory. Homepage Lyon, France: IARC; 2019 [cited 2019 Oct 21]. Available from: http://gco.iarc.fr/.

3 International Agency for Research on Cancer. Cancer Today: data visualization tools for exploring the global cancer burden in 2018. Lyon, France: World Health Organization; 2019 [cited 2019 Oct 21]. Available from: http://gco.iarc.fr/today/home.

4 Stein CJ, Colditz GA. Modifiable risk factors for cancer. Br J Cancer. 2004;90(2):299-303.

5 World Health Organization. Noncommunicable diseases progress monitor 2017. Geneva, Switzerland; 2017 [cited 2019 Oct 21] Available from: https://www.who.int/nmh/ ncd-tools/definition-targets/en/.

6 International Agency for Research on Cancer. Monographs on the evaluation of carcinogenic risks to humans: vol. 42. Alcohol drinking. Lyon, France: International Agency for Research on Cancer; 1988.

7 International Agency for Research on Cancer. IARC monographs on the evaluation of carcinogenic risks to humans: vol. 96. Alcohol consumption and ethyl carbamate. Lyon, France: International Agency for Research on Cancer; 2010.

8 Rehm J, Soerjomataram I, Ferreira-Borges C, Shield KD. Does alcohol use affect cancer risk? Curr Nutr Rep. 2019;8(3):222-9.

9 Pflaum T, Hausler T, Baumung C, Ackermann S, Kuballa T, Rehm J, et al. Carcinogenic compounds in alcoholic beverages: an update. Arch Toxicol. 2016;90(10):2349-67.

10 International Agency for Research on Cancer Homepage; 2007 [cited 2019 Oct 21]. Available from: https://www.iarc.fr/.

11 Institut National Du Cancer. IARC monographs on the identification of carcinogenic hazards to humans; 2018 [cited 2019 Oct 21]. Available from: https://www.e-cancer.fr/.
12 International Agency for Research on Cancer. IARC Monographs on the evaluation of carcinogenic risks to humans 100E. Lyon, France: International Agency for Research on Cancer; 2012.

13 World Cancer Research Fund International. About the continuous update project (CUP); 2018 [cited 2019 Oct 09]. Available from: https: //www.wcrf.org/int/continuous-update-project.

14 Institut National Du Cancer. Homepage; 2018 [cited 2019 Oct 21]. Available from: https://www.e-cancer.fr/.

15 Institut National Du Cancer. Alcool et risque de cancers: état des lieux des données scientifiques et recommandations de santé publique. Boulogne-Billancourt, France: Institut National Du Cancer; 2007.

16 Bagnardi V, Rota M, Botteri E, Tramacere I, Islami F, Fedirko V, et al. Alcohol consumption and site-specific cancer risk: a comprehensive dose-response meta-analysis. $\mathrm{Br} \mathrm{J}$ Cancer. 2015;112(3):580-93.

17 GBD 2016 Alcohol Collaborators. Alcohol use and burden for 195 countries and territories, 1990-2016: a systematic analysis for the Global Burden of Disease Study 2016. Lancet. 2018;392(10152):1015-35.

18 Rehm J, Imtiaz S. A narrative review of alcohol consumption as a risk factor for global burden of disease. Subst Abuse Treat Prev Policy. 2016;11(1):37.

19 Turati F, Galeone C, Rota M, Pelucchi C, Negri E, Bagnardi V, et al. Alcohol and liver cancer: a systematic review and meta-analysis of prospective studies. Ann Oncol. 2014;25(8): 1526-35.

20 World Health Organization. Global status report on alcohol and health 2018. Geneva, Switzerland: World Health Organization; 2018 [cited 2019 Oct 21]. Available from: https: //www.who.int/substance_abuse/publications/global_alcohol_report/en/.
21 Rehm J, Shield KD, Weiderpass E. Alcohol consumption. A leading risk factor for cancer. In: Wild CP, Weiderpass, E, Stewart, BW, editors. World cancer Report: cancer research for cancer prevention. Lyon, France: International Agency for Research on Cancer; 2020. p. 68-76.

22 Rehm J, Sherk A, Shield KD, Gmel G. Risk relations between alcohol use and non-injury causes of death. Toronto, ON: Centre for Addiction and Mental Health; 2017 [cited 2019 Oct 21]. Available from: https://www.camh. $\mathrm{ca} /-/$ media/files/pdfs---reports-and-books--research/camh-risk-relations-between-alcohol-use-and-non-injury-causes-of-deathsept2017-pdf.pdf?la=en\& hash=393C0B60D26 A218F2512C39C1B61EFCE0FCC5128.

23 Shield K, Manthey J, Rylett M, Probst C Wettlaufer A, Parry CDH, et al. National, regional, and global burdens of disease from 2000 to 2016 attributable to alcohol use: a comparative risk assessment study. Lancet Public Health. 2020;5(1):E51-61.

24 Marron M, Boffetta P, Zhang ZF, Zaridze D, Wünsch-Filho V, Winn DM, et al. Cessation of alcohol drinking, tobacco smoking and the reversal of head and neck cancer risk. Int J Epidemiol. 2010;39(1):182-96.

25 Schütze M, Boeing H, Pischon T, Rehm J, Kehoe T, Gmel G, et al. Alcohol attributable burden of incidence of cancer in eight European countries based on results from prospective cohort study. BMJ. 2011;342:d1584.

26 World Cancer Research Fund International, American Institute for Cancer Research. Continuous Update Project report: food, nutrition, physical activity, and the prevention of liver cancer. London, UK: World Cancer Research Fund International; 2015.

27 Grundy A, Poirier AE, Khandwala F, McFadden A, Friedenreich CM, Brenner DR. Cancer incidence attributable to alcohol consumption in Alberta in 2012. CMAJ open. 2016; 4(3):E507.

28 Shield KD, Soerjomataram I, Rehm J. Alcohol use and breast cancer: a critical review. Alcohol Clin Exp Res. 2016;40(6):1166-81. 
29 Hamajima N, Hirose K, Tajima K, Rohan T, Calle EE, Heath CW Jr, et al. Alcohol, tobacco and breast cancer: collaborative reanalysis of individual data from 53 epidemiological studies, including 58,515 women with breast cancer and 95,067 women without the disease. $\mathrm{Br}$ J Cancer. 2002;87(11):1234-45.

30 Bagnardi V, Rota M, Botteri E, Tramacere I, Islami F, Fedirko V, et al. Light alcohol drinking and cancer: a meta-analysis. Ann Oncol. 2013;24(2):301-8.

31 Choi YJ, Myung SK, Lee JH. Light alcohol drinking and risk of cancer: a meta-analysis of cohort studies. Cancer Res Treat. 2018;50(2): 474-87.

32 Allen NE, Beral V, Casabonne D, Kan SW, Reeves GK, Brown A, et al. Moderate alcohol intake and cancer incidence in women. J Natl Cancer Inst. 2009;101(5):296-305.

33 Rehm J, Gmel GE, Gmel G, Hasan OSM, Imtiaz S, Popova S, et al. The relationship between different dimensions of alcohol use and the burden of disease-an update. Addiction. 2017;112(6):968-1001.

34 Skog OJ. The prevention paradox revisited. Drug Alcohol Rev. 1999;11(3):227-9.

35 Manthey J, Shield KD, Rylett M, Hasan OSM, Probst C, Rehm J. Global alcohol exposure between 1990 and 2017 and forecasts until 2030: a modelling study. Lancet. 2019;393(10190): 2493-502.

36 Kreitman N. Alcohol consumption and the preventive paradox. Br J Addict. 1986;81(3): 353-63.

37 Rose G. Sick individuals and sick populations 1985. Bull World Health Organ. 2001;79(10): 990-6.

38 Keyes KM, Galea S. Population health science. Oxford, UK: Oxford University Press 2016.

39 Soerjomataram I, Shield K, Marant-Micallef C, Vignat J, Hill C, Rogel A, et al. Cancers related to lifestyle and environmental factors in France in 2015. Eur J Cancer. 2018;105:10313.

40 Rehm J, Manthey J, Shield KD, Ferreira-Borges $C$. Trends in substance use and in the attributable burden of disease and mortality in the WHO European region, 2010-16. Eur J Public Health. 2019;29(4):723-8.

41 World Health Organization Regional Office for Europe. Status report on alcohol consumption, harm and policy responses in 30 European countries; 2019 [cited 2019 May 20]. Available from: http://www.euro.who. int/en/health-topics/disease-prevention/alcohol-use/publications/2019/status-reporton-alcohol-consumption,-harm-and-policyresponses-in-30-european-countries-2019.

42 ECIS - European Cancer Information System. Measuring cancer burden and its time trends across Europe; 2018 [cited 2019 Oct 23]. Available from: https://ecis.jrc.ec.europa $\mathrm{eu} /$.
43 Scheideler JK, Klein WMP. Awareness of the link between alcohol consumption and cancer across the world: a review. Cancer Epidemiol Biomarkers Prev. 2018;27(4):429-37.

44 Wiseman KP, Klein WMP. Evaluating correlates of awareness of the association between drinking too much alcohol and cancer risk in the United States. Cancer Epidemiol Biomarkers Prev. 2019;28(7):1195-201.

45 Rehm J, Roerecke M. Cardiovascular effects of alcohol consumption. Trends Cardiovasc Med. 2017;27(8):534-8.

46 Petticrew M, Maani Hessari N, Knai C, Weiderpass E. How alcohol industry organisations mislead the public about alcohol and cancer. Drug Alcohol Rev. 2018;37(3):29303.

47 Rehm J, Shield KD. Global burden of alcohol use disorders and alcohol liver disease. Biomedicines. 2019;7(4):99.

48 Whiteman DC, Wilson LF. The fractions of cancer attributable to modifiable factors: a global review. Cancer Epidemiol. 2016;44: 203-21.

49 Llopis EJ, Kokole D, Neufeld M, Hasan OSM Rehm J. Evidence synthesis report on alcohol labelling. Copenhagen: WHO Health Services Network; In press.

50 Stockwell T. A review of research Into the impacts of alcohol warning labels on attitudes and behaviour British Colombia. Canada: Centre for Addictions Research of BC; 2006 [cited 2019 Oct 24]. Available from: https:// dspace.library.uvic.ca/bitstream/handle/1828/4785/AlcoholWarningLabels2006. pdf?s.

51 Hammond D. Health warning messages on tobacco products: a review. Tob Control. 2011;20(5):327-37.

52 Global Tobacco Control. State of evidence review: health warning labels on tobacco. Baltimore, MD: Institute for Global Tobacco Control; 2013 [cited 2019 Oct 24]. Available from: https: //www.who.int/healthinfo/global_burden_disease/en/.

53 Kane L. Warning labels on alcohol in Yukon removed after pushback from liquor companies. Toronto, Ontario: Global News; 2018 (posted January 3) [cited 2019 Oct 24]. Available from: https: //globalnews.ca/ news/3944739/warning-labels-alcohol-removed/.

54 Lachenmeier DW, Kanteres F, Rehm J. Epidemiology-based risk assessment using the benchmark dose/margin of exposure approach: the example of ethanol and liver cirrhosis. Int J Epidemiol. 2010;40(1):210-8.

55 European commission CORDIS EU Research Results. Final report summary: alcohol measures for public health research alliance (AMPHORA). Brussels, Belgium: European Commission; 2013 [cited 2019 Oct 24]. Available from: https://cordis.europa.eu/project/rcn/ 92876/reporting/en.

56 Wakefield MA, Loken B, Hornik RC. Use of mass media campaigns to change health behaviour. Lancet. 2010;376(9748):1261-71.
57 Babor TF, Caetano R, Casswell S, Edwards G, Giesbrecht N, Graham K, et al. Alcohol: no ordinary commodity. Research and public policy. 2nd ed. Oxford, London: Oxford University Press; 2010.

58 EU Cancer Plan - Fact Sheet. Europe's beating cancer plan; 2020 [cited $2020 \mathrm{Feb}$ 13] Available from: https://ec.europa.eu/health/ sites/health/files/non_communicable_diseases/docs/ev_20200204_factsheet_en.pdf.

59 World Cancer Research Fund and American Institute for Cancer Research. Food, nutrition, physical activity, and the prevention of cancer: a global perspective. Washington, DC: American Institute for Cancer Research; 2007

60 World Cancer Research Fund International, American Institute for Cancer Research. Continuous update project report: diet, nutrition, physical activity and oesophageal cancer. London, UK: World Cancer Research Fund International; 2016.

61 World Cancer Research Fund International, American Institute for Cancer Research. Continuous update project report: food, nutrition, physical activity, and the prevention of colorectal cancer. London, UK; 2011.

62 World Cancer Research Fund International, American Institute for Cancer Research. Continuous update project report: food, nutrition, physical activity, and the prevention of breast cancer. London, UK; 2011.

63 World Cancer Research Fund International, American Institute for Cancer Research. Continuous update project report: food, nutrition, physical activity, and stomach cancer. London, UK: World Cancer Research Fund International; 2016.

64 World Cancer Research Fund International American Institute for Cancer Research. Continuous update project report: diet, nutrition, physical activity and gallbladder cancer. London, UK: World Cancer Research Fund International; 2015.

65 World Cancer Research Fund International, American Institute for Cancer Research. Continuous update project report: food, nutrition, physical activity, and the prevention of pancreatic cancer. London, UK; 2012.

66 World Cancer Research Fund International American Institute for Cancer Research. Continuous update project report: food, nutrition, physical activity, and prostate cancer. London, UK; 2014

67 World Cancer Research Fund International, American Institute for Cancer Research. Continuous update project report: diet, nutrition, physical activity and kidney cancer. London, UK: World Cancer Research Fund International; 2015.

68 Rehm J, Kehoe T, Gmel G, Stinson F, Grant B, Gmel G. Statistical modeling of volume of alcohol exposure for epidemiological studies of population health: the US example, Popul Health Metr. 2010;8(1):3. 